\title{
Níveis de Proteína Bruta e Suplementação de Aminoácidos em Rações para Leitoas Mantidas em Ambiente de Conforto Térmico dos 30 aos 60 kg1
}

\author{
Uislei Antonio Dias Orlando ${ }^{2}$, Rita Flávia Miranda de Oliveira ${ }^{3}$, Juarez Lopes Donzele ${ }^{3}$, Aloízio \\ Soares Ferreira ${ }^{3}$, Francisco Carlos de Oliveira Silva ${ }^{4}$, Rafaela Antonia Ramos Generoso ${ }^{5}$, \\ Roberta Gomes Marçal Vieira Vaz ${ }^{6}$, Jefferson Costa de Siqueira ${ }^{5}$
}

\begin{abstract}
RESUMO - Foi conduzido um experimento para determinar o nível de proteína bruta (PB) das rações com suplementação de aminoácidos para leitoas mestiças (Landrace x Large White) mantidas em ambiente de conforto térmico. Os animais (peso médio inicial de $30,1 \mathrm{~kg}$ ) foram distribuídos em delineamento experimental inteiramente ao acaso, com cinco tratamentos (19, 18, 17, 16 e 15\% de PB com suplementação de lisina metionina, triptofano, treonina e valina, para se manter a mesma qualidade proteica), cinco repetições e dois animais por unidade experimental. As rações experimentais foram fornecidas à vontade até o final do experimento, quando os animais atingiram peso médio de $60,3 \mathrm{~kg}$. O nível de PB da ração influenciou o ganho de peso diário e a conversão alimentar, mas não influiu no consumo de ração diário. A deposição de proteína não variou entre os níveis de 19 e $16 \%$ de PB da ração, enquanto os animais que consumiram a ração com menor nível de PB (15\%) apresentaram o menor valor. Os tratamentos não influenciaram os pesos absoluto e relativo dos órgãos avaliados. Concluiu-se que o nível de PB da ração para leitoas dos 30 aos $60 \mathrm{~kg}$ mantidas em ambiente de conforto térmico pode ser reduzido de 19 para $15 \%$, sem prejudicar o desempenho, desde que as rações sejam devidamente suplementada com os aminoácidos essenciais limitantes.
\end{abstract}

Palavras-chave: ambiente térmico, composição de carcaça, desempenho, proteína ideal, vísceras

\section{Crude Protein Levels of Ration with Amino Acid Supplementation to Gilts Maintained in a Thermal Comfort Environment from 30 to $60 \mathrm{~kg}$}

\begin{abstract}
An experiment was conduced to determine the crude protein (CP) level in diets with amino acids supplementation for gilts maintained in a thermal comfort environment. Fifty crossbreed crossbred gilts (Landrace x Large White) with initial average weight of $30.1 \mathrm{~kg}$ were allotted to a completely randomized experimental design, with five treatments $(19,18,17,16$ and $15 \%$ of $\mathrm{CP}$ with supplementation of lysine, methionine, tryptophan, threonine and valine to maintain the same protein quality) five replicates and two animals per experimental unit. The experimental rations were fed ad libitum until the end of the experiment, when the animals reached the average weight of $60.3 \mathrm{~kg}$. The CP level of the ration influenced the daily weight gain and the feed:gain ratio however the treatments did not influence the daily feed intake. The protein deposition (PD) did not change from 19 to $16 \%$ of CP of the diet. However the animals that fed diet with smaller level showed the lowest value of PD. The treatments did not influence the absolute and relative weights of all evaluated organs. It was concluded that the crude protein level, for gilts from 30 to $60 \mathrm{~kg}$, maintained in thermal comfort environment can be reduced from 19 to $15 \%$ with no negative effect on performance since rations are supplemented with limiting essential amino acids
\end{abstract}

Key Words: carcass composition, ideal protein, organs, performance, thermal environment

\section{Introdução}

A suinocultura representa importante segmento do agronegócio brasileiro. Deve-se, portanto, buscar alternativas para reduzir custos com alimentação (70\% dos custos de produção) e, por conseguinte, aumentar a rentabilidade da exploração. Entretanto, apesar de sua importância econômica, sabe-se que a exploração suinícola, por se caracterizar por alta concentração de animais em pequenas áreas, tem impacto negativo de poluição ambiental, em razão do grande volume de dejetos produzido. Atualmente, devem ser priorizadas estratégias nutricionais que objetivem reduzir o potencial poluente dos dejetos de suínos; uma alternativa é a redução do nível de proteína bruta da ração com a suplementação de aminoácidos sintéticos (Baker et al., 1993; Cromwell 1996; Reese \& Koelsch, 2000; Carlson, 2001; Ford,

\footnotetext{
${ }^{1}$ Parte da tese de Mestrado do primeiro autor - Projeto apoiado pela Ajinomoto.

2 Doutor em Zootecnia, Perdigão (und@perdigao.com.br).

3 Professor do DZO/UFV. E.mail: flavia@ufv.br; donzele@ufv.br

4 Pesquisador da EPAMIG.

5 Estudante do curso de Zootecnia do DZO/UFV.

${ }^{6}$ Estudante de Doutorado do DZO/UFV.
} 
2003), uma vez que estes ingredientes podem reduzir acentuadamente as perdas de nitrogênio para o ambiente, sem reflexo negativo no desempenho dos animais. De acordo com Kerr \& Easter (1995), cada $1 \%$ de redução da proteína da ração diminui em $8 \%$ o nitrogênio excretado nos dejetos.

Um ponto importante na utilização da técnica de redução de proteína bruta, a partir da substituição por aminoácidos sintéticos, é que as rações com aminoácidos são mais próximas do perfil de proteína ideal e, por conseguinte, diminuem as perdas de nitrogênio nos dejetos. Ford (2003) mostrou que a utilização de quatro aminoácidos sintéticos (lisina, metionina, treonina e triptofano) levou à redução de $40 \%$ na excreção de nitrogênio nas fezes e urina, melhorando o aspecto sanitário das instalações e as condições de trabalho para os funcionários das granjas.

Como o desempenho e a fisiologia dos animais podem ser influenciados pelo ambiente térmico em que estes são criados, a redução do nível de proteína da ração pode proporcionar resultados diferentes em razão do ambiente no qual os animais são criados (Oliveira, 1996; Edmonds et al., 1998).

Segundo Möhn \& De Lange (1998), quando os animais são mantidos em ambiente livre de estresse, com adequado consumo de nutrientes essenciais, eleva-se a deposição de proteína e, conseqüentemente, o ganho de peso, com o consumo de energia até um limite máximo geneticamente determinado.

Este estudo foi conduzido para avaliar os efeitos da redução da proteína bruta em rações com a suplementação de aminoácidos sobre o desempenho, a composição de carcaça e o peso de vísceras de leitoas mestiças dos 30 aos $60 \mathrm{~kg}$ mantidas em ambiente de conforto térmico $\left(20^{\circ} \mathrm{C}\right)$.

\section{Material e Métodos}

O experimento foi conduzido no Setor de Suinocultura do Departamento de Zootecnia do Centro de Ciências Agrárias da Universidade Federal de Viçosa, em Viçosa, MG.

Cinqüenta leitoas mestiças (Landrace $\mathrm{x}$ Large White), com peso inicial de 30,1 $\pm 0,63 \mathrm{~kg}$, foram distribuídas em delineamento experimental inteiramente ao acaso, com cinco tratamentos $(19,18,17,16$ e $15 \%$ de proteína bruta na ração com suplementação de lisina metionina, triptofano, treonina e valina, para se manter a mesma qualidade protéica), cinco repetições e dois animais por unidade experimental.
Os animais foram alojados em gaiolas metálicas, suspensas, com pisos e laterais telados, providas de comedouro semi-automático e bebedouro tipo chupeta, e mantidos em sala de alvenaria com janelas de vidro do tipo basculante, forro de madeira e cobertura com telha de barro.

A temperatura interna da sala foi mantida por um conjunto de seis campânulas elétricas, distribuídas em dois corredores, a aproximadamente $40 \mathrm{~cm}$ acima do piso, e por dois aparelhos de ar condicionado de 30.000 BTU cada, controlados por sensores instalados no centro da sala, regulados para temperatura de $20^{\circ} \mathrm{C}$.

A temperatura e a umidade relativa internas da sala foram monitoradas diariamente durante o período experimental, três vezes ao dia $(8,13 \mathrm{e} 18 \mathrm{~h})$, por meio de termômetro de máxima e mínima, termômetro de bulbo seco e bulbo úmido e termômetro de globo negro mantidos em uma gaiola vazia a uma altura correspondente à meia altura do corpo dos animais.

Os valores registrados foram convertidos no índice de temperatura de globo e umidade (ITGU), segundo Buffington et al. (1981), caracterizando o ambiente térmico em que os animais foram mantidos.

As rações experimentais e suas composições centesimal e nutricional calculadas encontram-se na Tabela 1. As rações foram formuladas à base de milho e farelo de soja e suplementadas com minerais e vitaminas para serem isoenergéticas $(3.400 \mathrm{kcal}$ de $\mathrm{ED} / \mathrm{kg}$ ) e isolisínicas digestíveis $(0,875 \%)$. Os níveis de $\mathrm{PB}$ das rações experimentais foram obtidos ajustando-se as quantidades de milho e de farelo de soja. A fim de tornar as rações isolisínicas digestível, foi adicionada lisina sintética (L-lisina-HCl 78,5\%) à medida que se reduziu o nível de PB. Os demais aminoácidos (treonina, metionina, triptofano e valina) foram suplementados à proporção que suas relações com a lisina digestível ficaram abaixo daquelas preconizadas na proteína ideal, de acordo com as recomendações de Füller (1996). Para o cálculo dos aminoácidos digestíveis dos ingredientes utilizados na formulação, foram aplicados os coeficientes de digestibilidade obtidos nas tabelas Rhodimet... (1993). As rações experimentais e a água foram fornecidas à vontade.

Ao término do período experimental, quando atingiram o peso médio de $60,3 \pm 1,94 \mathrm{~kg}$, os animais foram submetidos a jejum alimentar por 24 horas. Após o jejum, um animal de cada unidade experimental, com o peso mais próximo de $60 \mathrm{~kg}$, foi abatido, por

R. Bras. Zootec., v.34, n.1, p.134-141, 2005 
Tabela 1 - Composição centesimal e nutricional calculada das rações experimentais

Table 1 - Centesimal and nutritional calculated composition of the experimental rations

\begin{tabular}{|c|c|c|c|c|c|}
\hline \multirow[t]{2}{*}{$\begin{array}{l}\text { Ingredientes } \\
\text { Ingredients }\end{array}$} & \multicolumn{5}{|c|}{$\begin{array}{c}\text { Níveis de proteína bruta (\%) } \\
\text { Crude protein levels }\end{array}$} \\
\hline & 19 & 18 & 17 & 16 & 15 \\
\hline $\begin{array}{l}\text { Milho }(7,95 \% \mathrm{~PB})^{1} \\
\text { Corn }(7,95 \% \text { CP })\end{array}$ & 66,702 & 69,272 & 71,622 & 73,974 & 76,198 \\
\hline $\begin{array}{l}\text { Farelo soja }(45,6 \% \text { PB })^{1} \\
\text { Soybean meal }(45.6 \% C P)\end{array}$ & 29,975 & 27,192 & 24,593 & 21,994 & 19,417 \\
\hline $\begin{array}{l}\text { Óleo de soja } \\
\text { Soybeanil) }\end{array}$ & 0,667 & 0,735 & 0,820 & 0,896 & 1,032 \\
\hline $\begin{array}{l}\text { Fosfato bicálcico } \\
\text { Dicalcium phosphate }\end{array}$ & 1,100 & 1,151 & 1,204 & 1,256 & 1,310 \\
\hline $\begin{array}{l}\text { Calcário } \\
\text { Limestone }\end{array}$ & 1,020 & 1,010 & 0,999 & 0,985 & 0,972 \\
\hline $\begin{array}{l}\text { Mistura mineral } \\
\text { Mineral mix }\end{array}$ & 0,100 & 0,100 & 0,100 & 0,100 & 0,100 \\
\hline $\begin{array}{l}\text { Mistura vitamínica } \\
\text { Vitamin mix }\end{array}$ & 0,100 & 0,100 & 0,100 & 0,100 & 0,100 \\
\hline $\begin{array}{l}\text { Sal comum } \\
\text { Salt }\end{array}$ & 0,326 & 0,329 & 0,331 & 0,334 & 0,337 \\
\hline $\begin{array}{l}\text { BHT } \\
\text { L-Lisina } \mathrm{HCl}\end{array}$ & $\begin{array}{l}0,010 \\
-\end{array}$ & $\begin{array}{l}0,010 \\
0,081\end{array}$ & $\begin{array}{l}0,010 \\
0,157\end{array}$ & $\begin{array}{l}0,010 \\
0,233\end{array}$ & $\begin{array}{l}0,010 \\
0,309\end{array}$ \\
\hline $\begin{array}{l}L \text {-Lysine } \mathrm{HCl} \\
\text { DL-Metionina }\end{array}$ & - & 0,020 & 0,041 & 0,062 & 0,084 \\
\hline $\begin{array}{l}\text { DL-Methionine } \\
\text { L-Treonina }\end{array}$ & - & - & 0,023 & 0,056 & 0,090 \\
\hline $\begin{array}{l}\text { L-Threonine } \\
\text { L-Triptofano } \\
\text { L-Tryptophan }\end{array}$ & - & - & - & - & 0,010 \\
\hline L-Valina & - & - & - & - & 0,031 \\
\hline
\end{tabular}

L-Valine

Total

100,000

100,000

100,000

100,000

100,000

Composição nutricional calculada ${ }^{4}$

Nutritional calculated composition

$\mathrm{PB}(\%) \quad 19,07$

18,00

17,00

16,00

15,00

$C P$

$\mathrm{ED}(D E)(\mathrm{kcal} / \mathrm{kg}) \quad 3.400$

Lisina total $(\%)$

$3.400 \quad 3.400$

Total lysine

Lisina dig. (\%)

1,000

0,993

3.400

0,986

3.400

0,979

3.400

Digestible lysine

Relação Lis:PB (\%)

Lys: $C P$ ratio

Met+Cis dig. (\%)

Digestible methionine + cystine

Treonina dig. (\%)

Digestible threonine

Triptofano dig. (\%)

Digestible tryptophan

Isoleucina dig. (\%)

Digestible isoleucine

Valina dig. (\%)

Digestible valine

Cálcio (Calcium), \%

Fósforo total (\%)

0,875

0,875

5,24

0,553

5,52

0,551

0,642

0,606

0,203

0,189

0,727

0,682

0,875

5,80

0,551

0,595

0,175

0,639

0,745

0,705

0,760

0,760

0,540

0,540

0,170

0,170

0,760

0,540

0,170

${ }^{1}$ Análises realizadas no Laboratório de Nutrição Animal do DZO/UFV (Analyses were carried out at the Animal Nutrition Lab of UFV).

${ }^{2}$ Conteúdo/kg (Content/kg): $100 \mathrm{~g} \mathrm{Fe} ; 10 \mathrm{~g} \mathrm{Cu} ; 1 \mathrm{~g} \mathrm{Co} ; 40 \mathrm{~g} \mathrm{Mn} ; 100 \mathrm{~g} \mathrm{Zn;1,5} \mathrm{g} \mathrm{I;} 1.000 \mathrm{~g}$ excipiente (vehicle) q.s.p.

${ }^{3}$ Conteúdo/kg (Content/kg): vit A - 6.000.000 UI; $\mathrm{D}_{3}$ - 1.500.000 UI; E - 15.000 Ul; $\mathrm{B}_{1}$ - 1,35; $\mathrm{B}_{2}$ - 4 g; $\mathrm{B}_{6}$ - 2 g; ácido pantotênico (Pantotenic acid) - 9,35 g; vit $\mathrm{K}_{3}$ - 1,5 g; ácido nicotínico (Nicotinic acid) - 20,0 g; vit $\mathrm{B}_{12}-20,0 \mathrm{~g}$; ácido fólíco (Folic acid) - 0,6 g; biotina (Biotin) - 0,08 g; selênio (Selenium) - 0,3 g; excipiente (vehicle) q.s.p. - $1.000 \mathrm{~g}$.

${ }^{4}$ Composição nutricional calculada segundo Rostagno et al. (2000), exceto a proteína bruta. (Nutritional composition was calculated according to Rostagno et al. [2000], except for crude protein).

\section{R. Bras. Zootec., v.34, n.1, p.134-141, 2005}


desensibilização e sangramento. Em seguida, procedeu-se à toalete e à abertura da carcaça para retirada dos órgãos. O fígado, os rins e o intestino delgado foram colocados à sombra, para o escorrimento do sangue, por 20 minutos e, após, foram pesados.

Um grupo adicional de cinco leitoas com peso médio de $30,1 \pm 0,73 \mathrm{~kg}$ foi abatido, seguindo-se o mesmo procedimento de abate usado com os animais submetidos às rações experimentais, para determinação da composição da carcaça dos animais no início do experimento e posterior determinação da deposição de proteína na carcaça, conforme técnica descrita por Donzele et al. (1992).

As carcaças dos animais abatidos foram divididas longitudinalmente, e a metade esquerda de cada carcaça (incluindo cabeça e pés), sem as vísceras e o sangue, foi triturada por 15 minutos em "cutter" comercial de 30 HP e 1.775 revoluções por minuto. Após homogeneização do material triturado, foram retiradas amostras das carcaças, que foram estocadas em congelador $\mathrm{a}-12^{\circ} \mathrm{C}$. Ao se prepararem as amostras para as análises laboratoriais, em razão da alta concentração de gordura do material, procedeu-se à pré-secagem em estufa, com ventilação forçada a $\pm 60^{\circ} \mathrm{C}$, por 72 horas. Em seguida, foi realizado o pré-desengorduramento, a quente, em aparelho extrator do tipo "Soxlet", por quatro horas.

As amostras pré-secadas e pré-desengorduradas foram moídas e acondicionadas em vidros com tampa de polietileno devidamente identificados, para posteriores análises laboratoriais. A água e a gordura retiradas no preparo das amostras foram consideradas para fazer a correção dos valores das análises subseqüentes.

As análises de proteína das amostras foram realizadas no Laboratório de Nutrição Animal do Departamento de Zootecnia da UFV, de acordo com técnicas descritas em Silva (1990).

As análises estatísticas das variáveis de desempenho (ganho de peso, consumo de ração e conversão alimentar), de deposição de proteína nas carcaças e de pesos dos órgãos foram realizadas utilizando-se o programa computacional SAEG 8.0 (Sistema de Análises Estatísticas e Genéticas), desenvolvido na UFV (2000).

A avaliação da possibilidade de redução da proteína bruta da ração, com suplementação de aminoácidos, foi feita com base nos resultados de desempenho (ganho de peso, consumo de ração, conversão alimentar), nos consumos de lisina, de nitrogênio e de energia digestível diários, na eficiência de utilização de nitrogênio para ganho de peso e na deposição de proteína na carcaça, utilizando os modelos linear, quadrático e/ou descontínuo "Linear Reponse Plateau" - LRP, conforme o melhor ajuste obtido para cada variável.

\section{Resultados e Discussão}

A temperatura interna da sala manteve-se, durante o período experimental, em $20,2 \pm 1,5^{\circ} \mathrm{C}$, com umidade relativa de $71,8 \pm 6,6 \%$ e temperatura de globo negro de $20,3 \pm 1,5^{\circ} \mathrm{C}$. O índice de temperatura de globo e umidade (ITGU), calculado no período, foi de $66,7 \pm 1,9$. O valor de ITGU, que caracterizou o ambiente termoneutro neste trabalho, foi similar àqueles obtidos por Tavares et al. (2000) e Orlando (2001), com suínos de 30 aos $60 \mathrm{~kg}(69,1 \pm 1,19$ e 68,7 $\pm 0,93$, respectivamente).

Os resultados de desempenho, dos consumo de lisina, de energia digestível e de nitrogênio diários, da eficiência de utilização de nitrogênio para ganho e da deposição de proteína na carcaça das leitoas, mantidas em ambiente de conforto térmico dos 30 aos $60 \mathrm{~kg}$, são apresentados na Tabela 2.

Não se observou variação $(\mathrm{P}>0,05)$ nos valores de ganho de peso diário (GPD) a medida que se reduziu o nível de proteína das rações. Resultado semelhante foi obtido por Le Bellego et al. (2001) e Kerr et al. (2003a,b), que, avaliando a redução de níveis de proteína das rações de suínos em crescimento, mantidos em ambiente de termoneutralidade, também não observaram variação significativa no GPD dos animais, em razão dos níveis de proteína das rações.

Por outro lado, Pieterse et al. (2000), trabalhando com redução de proteína bruta de 20 para $14 \%$, e Figueroa et al. (2002), avaliando a redução de quatro pontos percentuais no nível de proteína bruta (16 para $12 \%$ ) em rações para suínos na fase de crescimento, em ambiente termoneutro, constataram melhora no GPD, em razão dos tratamentos. Em contrapartida, Gómez et al. (2002a) constataram piora no GPD dos suínos mantidos em condições de termoneutralidade, quando o nível de PB da ração foi reduzido em 4,2 pontos percentuais.

A diferença de resposta do GPD dos animais, observada entre os dados deste estudo com aqueles obtidos por Gómez et al. (2002a) pode estar relacionada ao fato de que estes autores não adicio-

R. Bras. Zootec., v.34, n.1, p.134-141, 2005 
Tabela 2 - Resultados de desempenho, consumos de lisina e energia digestíveis (ED) e nitrogênio (N), eficiência de utilização de nitrogênio para ganho (EUNG) e deposição diária de proteína na carcaça de leitoas dos 30 aos $60 \mathrm{~kg}$ mantidas em ambiente de conforto térmico

Table 2 - Results of performance, intakes of digestible lysine and energy (DE) and nitrogen ( $N$ ), efficiency of $N$ utilization to gain (EUNG) and daily deposition of protein in carcass of gilts from 30 to $60 \mathrm{~kg}$ maintained in a thermal comfort environment

\begin{tabular}{|c|c|c|c|c|c|c|}
\hline \multirow[t]{2}{*}{$\begin{array}{l}\text { Variáveis } \\
\text { Variables }\end{array}$} & \multicolumn{5}{|c|}{$\begin{array}{l}\text { Proteína bruta }(\%) \\
\text { Crude protein }\end{array}$} & \multirow[t]{2}{*}{$\mathrm{CV}(\%)$} \\
\hline & 19 & 18 & 17 & 16 & 15 & \\
\hline $\begin{array}{l}\text { Ganho de peso }(\mathrm{g} / \mathrm{d}) \\
\text { Weight gain }\end{array}$ & 813 & 856 & 943 & 808 & 883 & 8,74 \\
\hline $\begin{array}{l}\text { Consumo de ração }(\mathrm{g} / \mathrm{d}) \\
\text { Feed intake }\end{array}$ & 1811 & 1921 & 1943 & 1805 & 1921 & 8,42 \\
\hline $\begin{array}{l}\text { Conversão alimentar }(\mathrm{g} / \mathrm{g}) \\
\text { Feed/gain ratio }\end{array}$ & 2,23 & 2,24 & 2,06 & 2,24 & 2,18 & 5,02 \\
\hline $\begin{array}{l}\text { Consumo de lisina dig. }(\mathrm{g} / \mathrm{d}) \\
\text { Digestible lysine intake }\end{array}$ & 15,9 & 16,8 & 17,0 & 15,8 & 16,8 & 8,42 \\
\hline $\begin{array}{l}\text { Consumo ED } \\
\text { Energyintake }(\mathrm{kcal} / \mathrm{d})\end{array}$ & 6158 & 6531 & 6606 & 6137 & 6532 & 8,42 \\
\hline $\begin{array}{l}\text { Consumo de } \mathrm{N}(\mathrm{g} / \mathrm{d})^{1} \\
\text { Nitrogen intake }\end{array}$ & 55,3 & 55,3 & 52,9 & 46,2 & 46,1 & 8,46 \\
\hline EUNG $(\mathrm{gGP} / \mathrm{gN})^{1}$ & 14,7 & 15,5 & 17,8 & 17,5 & 19,2 & 4,85 \\
\hline Proteína (Protein) $(\mathrm{g} / \mathrm{d})^{2}$ & 117 & $\begin{array}{l}\mathrm{De} \\
128\end{array}$ & $\begin{array}{l}\text { la carc } \\
124\end{array}$ & $\begin{array}{l}\text { positic } \\
123\end{array}$ & $\begin{array}{l}\text { uss) } \\
100\end{array}$ & 12,09 \\
\hline
\end{tabular}

naram o aminoácido valina à ração com menor nível de $\mathrm{PB}$, o que resultou em relação de valina digestível:lisina digestível abaixo da utilizada neste trabalho. Esta hipótese esta consistente com o relato destes mesmos autores de que a inadequada ingestão de um quinto aminoácido essencial que não lisina, metionina, treonina e triptofano, pode ter sido a causa de uma piora no desempenho.

O nível de $\mathrm{PB}$ da ração não influenciou $(\mathrm{P}>0,05)$ o consumo de ração diário (CRD) que neste estudo correspondeu a 4,2\% do peso corporal médio dos animais. As respostas de CRD obtidas foram semelhantes às observadas por diversos autores (Tuitoek et al., 1997a; Canh et al., 1998; Pieterse et al., 2000; Le Bellego, et al., 2001; De La Llata et al., 2002; Figueroa et al., 2002; Gómez et al., 2002a; Kerr et al., 2003b) que também não constataram efeito do nível de PB da ração sobre o CRD dos animais.

Apesar de não ter variado significativamente, constatou-se que o CRD dos animais que receberam a ração com níveis reduzidos de $\mathrm{PB}$, com exceção daquele dos animais que receberam o tratamento correspondente ao nível de $16 \%$ de PB, foi em média $6,5 \%$ maior em relação aos dos animais que receberam a ração com $19 \%$ de PB. O menor valor absoluto de consumo de ração observado nos animais que receberam a ração com maior nível de PB está consistente com os resultados obtidos por Le Bellego \& Noblet (2002).

Considerando que o imbalanço de aminoácidos pode influenciar negativamente o CRD dos animais, conforme relatado por Le Bellego \& Noblet (2002), pode se deduzir que o perfil de aminoácidos das rações utilizadas neste estudo provavelmente tenha sido adequado.

Os valores de conversão alimentar (CA) não variaram $(\mathrm{P}<0,05)$ entre os tratamentos, o que está em acordo com os resultados obtidos por Tuitoek et al. (1997a) e de Canh et al. (1998), que não observaram variação significativa na $\mathrm{CA}$ dos suínos em crescimento em razão da diminuição do nível de PB da ração. Mais recentemente, Kerr et al. (2003b), trabalhando com suínos na fase de crescimento, em ambiente termoneutro, também não constataram variação significativa na CA dos animais quando o nível de proteína bruta da ração foi reduzido de 16 para até $12 \%$, com suplementação de aminoácidos.

Por outro lado, Kendall et al. (1998) e Gómez et al. (2002a) observaram piora na CA com a redução de 4,5 a 4,2 pontos percentuais no nível de PB das 
rações, respectivamente. Nestes estudos, a possível deficiência de um quinto aminoácido foi considerada pelos autores determinante na piora do desempenho. Esta proposição está em consonância com o relato de Kendall et al. (1998) de que a suplementação de lisina, metionina, treonina e triptofano não é suficiente para assegurar bom desempenho dos animais, quando o nível de PB da ração foi reduzido em mais de três pontos percentuais.

A variação de resultados de CA observada entre os trabalhos pode estar relacionada à diferença no perfil de aminoácidos essenciais com a lisina e a genética dos animais, entre outros fatores. Com relação à genética dos animais, Mahan \& Shieds (1998) relataram que, em razão de o tecido muscular provavelmente exigir mais lisina e, possivelmente, outros aminoácidos essenciais do que outros tecidos, a relação dos aminoácidos essenciais com a lisina, na ração de suínos com alto potencial para deposição de carne na carcaça, pode ser diferente daquela de suínos de médio ou baixo potencial.

Os consumos de lisina (CLD) e de energia digestível (CED) diários não foram influenciados ( $\mathrm{P}>0,05)$ pela redução do nível de $\mathrm{PB}$ da ração. Resultados semelhantes foram obtidos por Ferreira (2001), em trabalho conduzido para avaliar redução dos níveis de PB das rações para suínos na fase de crescimento. Estes resultados podem ser explicados pelo CRD, que não diferiu entre os tratamentos, uma vez que as rações foram isoenergéticas e isolisínicas.

Os tratamentos influenciaram $(\mathrm{P}<0,01)$ de forma linear o consumo de nitrogênio diário $(\mathrm{N})$ que diminuiu segundo a equação $Y=5,30239+2,69463 \mathrm{~PB}$ $\left(\mathrm{r}^{2}=0,86\right)$. Porém, a eficiência de utilização de nitrogênio para ganho $(E U N G)$ aumentou $(\mathrm{P}<0,01)$ de forma linear de acordo com a equação $Y=35,0757-1,06565 \mathrm{~PB}$ $\left(\mathrm{r}^{2}=0,91\right)$, à medida que se diminuiu o nível de $\mathrm{PB}$ das rações, e os animais alimentados com ração contendo $15 \%$ de $\mathrm{PB}$ apresentando EUNG superior $(30,6 \%)$ à obtida com os animais que receberam a ração com $19 \%$ de PB em 7,9\%.

Resultado similar de EUNG foi também observado por Kerr \& Easter (1995), Tuitoek et al. (1997a), Canh et al. (1998) e Figueroa et al. (2002). Da mesma forma, Ferreira (2001), em estudo conduzido no Brasil, observou melhora gradativa na EUNG com a redução do nível de $\mathrm{PB}$ da ração. Essa coerência de resultados entre os trabalhos está em conformidade com os dados de Shriver et al. (2003), em que a redução de $\mathrm{PB}$ da ração, com adequada suplementação de aminoácidos, diminuiu significativamente a excreção de nitrogênio, sem influir no desempenho dos suínos em crescimento e terminação. Ainda de acordo com Chung \& Baker (1992), a EUNG aumenta quando o perfil de aminoácido da ração estiver o mais próximo do ideal.

A deposição de proteína (DP) na carcaça foi influenciada $(\mathrm{P}<0,01)$ de forma quadrática pela redução dos níveis de $\mathrm{PB}$ das rações, com o melhor resultado obtido no nível de 17,4\% de PB (Figura 1).

O aumento na DP observado entre os níveis de PB de 19 a 17,4\%, neste estudo, difere dos resultados de Tuitoek et al. (1997b) e de Le Bellego \& Noblet (2002), que não verificaram alteração na DP dos animais que receberam a ração com menor nível de $\mathrm{PB}$ em relação aos que receberam os tratamentos com PB na forma intacta. Por outro lado, o menor valor de DP ocorrido no menor nível de PB avaliado nesse estudo (15\%) está em conformidade com o resultado de Gómez et al. (2002b), que, avaliando a composição da carcaça de suínos em crescimento recebendo rações formuladas com PB intacta $(15,9 \%)$ e com baixa PB $(11,7 \%)$ suplementadas com aminoácidos, observaram menor valor de DP nos

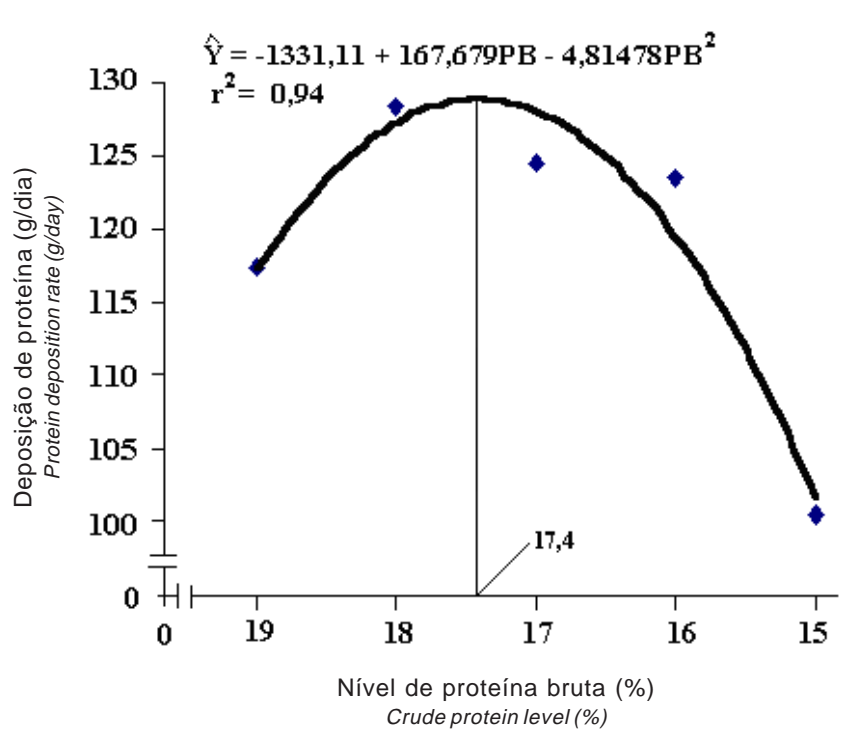

Figura 1 - Efeito da redução do nível de proteína bruta da ração e suplementação de aminoácidos sobre a deposição de proteína na carcaça de leitoas dos 30 aos $60 \mathrm{~kg}$, mantidas em ambiente de conforto térmico.

Figure 1 - Effect of reduction of dietary crude protein level with amino acids suplementation on protein deposition in carcass of gilts from 30 to $60 \mathrm{~kg}$ maintained in a thermal comfort environment. 
Tabela 3 - Pesos absolutos ( $\mathrm{g}$ ) e relativos (\% da carcaça) do fígado, rins e intestino de leitoas de $60 \mathrm{~kg}$ mantidas em ambiente de conforto térmico

Table 3 - Absolute $(\mathrm{g})$ and relative (\% of carcass) weights of liver, kidneys and gut of gilts of $60 \mathrm{~kg}$ maintained in a thermal comfort environment

\begin{tabular}{|c|c|c|c|c|c|c|}
\hline \multirow[t]{2}{*}{$\begin{array}{l}\text { Variáveis } \\
\text { Variables }\end{array}$} & \multicolumn{5}{|c|}{ Proteína bruta (\%) } & \multirow[t]{2}{*}{$\mathrm{CV}(\%)$} \\
\hline & 19 & 18 & 17 & 16 & 15 & \\
\hline \multicolumn{7}{|c|}{ Peso absoluto (g) (Absolute weight) } \\
\hline Fígado (Liver) & 1193 & 1296 & 1244 & 1261 & 1114 & 8,67 \\
\hline Rins (Kidneys) & 241 & 234 & 275 & 236 & 272 & 12,33 \\
\hline Intestino (Gut) & 1141 & 1239 & 1267 & 1159 & 1233 & 8,69 \\
\hline \multicolumn{7}{|c|}{ Peso relativo (\%) (Relative weight) } \\
\hline Fígado (Liver) & 2,61 & 2,79 & 2,71 & 2,71 & 2,38 & 9,29 \\
\hline Rins (Kidneys) & 0,52 & 0,51 & 0,61 & 0,51 & 0,59 & 12,62 \\
\hline Intestino $(G u t)$ & 2,47 & 2,67 & 2,79 & 2,48 & 2,64 & 10,93 \\
\hline
\end{tabular}

CV - Coeficiente de variação (Coefficient of variation).

animais que receberam a ração com o mais baixo nível proteico mais suplementação aminoacídica.

Os resultados de pesos absoluto e relativo dos diferentes órgãos avaliados (fígado, rins e intestino) são apresentados na Tabela 3.

Apesar da participação direta do fígado e dos rins no processo de degradação dos aminoácidos em excesso, não se observou efeito $(\mathrm{P}>0,05)$ da redução do nível de $\mathrm{PB}$ da ração e, conseqüentemente, da concentração total de aminoácidos das rações sobre os pesos absoluto e relativo de nenhum dos órgãos avaliados.

De forma semelhante, Ferreira (2001), Gómez et al. (2002b) e Le Belego \& Noblet (2002) não constataram variação significativa do peso do fígado e dos rins em razão da redução do nível de PB da ração. Em contrapartida, Chen et al. (1998) verificaram diminuição nos pesos do fígado e rins, enquanto Kerr et al. (2003b), redução no peso dos rins, sem variação no peso do fígado dos suínos em decorrência de decréscimo do nível de PB da ração.

A princípio, não há uma explicação biológica para justificar a falta de consistência de resultados entre os trabalhos quanto ao efeito da redução do nível de PB da ração sobre o peso de órgãos de suínos.

\section{Conclusões}

O nível de $\mathrm{PB}$ da ração para leitoas mestiças dos 30 aos $60 \mathrm{~kg}$ mantidas em ambiente de conforto térmico $\left(20^{\circ} \mathrm{C}\right)$ pode ser reduzido em $4 \%(19$ para $15 \%$ ), sem prejudicar o desempenho dos animais, desde que as rações sejam devidamente suplementadas com os aminoácidos essenciais limitantes.

\section{Literatura Citada}

BAKER, D.H.; HAHN, J.D.; CHUNG, T.K. Nutrition and growth: the concept and application of an ideal protein for swine growth. In: HOLLIS, G.R. (Ed.) Growth of the pig. Illinois: CAB International, 1993. p.133-139.

BUFFINGTON, D.E.; COLAZZO-AROCHO, A.; CANTON, G.H. et al. Black globe-humidity index (BGHI) as comfort equation for dairy cows. Transaction of the ASAE, v.24, p.711-714, 1981 .

CANH, T.T.; AARNINK, A.J.A.; SCHUTTE, J.B. et al. Dietary protein affects nitrogen excretion and ammonia emission from slurry of growing-finishing pigs. Livestock Production Science, v.56, p.181-191, 1998.

CARLSON, M. Amino acid manipulation and phytase utilization impact on nitrogen and phosphorus excretion. Production Information for Missori Pork Producers, p.1-5, 2001.

CHEN, H.Y.; MILLER, P.S.; LEWIS, A.J. The effect of protein intake on growth performance, plasma urea concentration, liver weight, and arginase activity of finishing barrows and gilts. Nebraska Swine Report, p.34-35, 1998.

CHUNG, T.K.; BAKER, D.H. Ideal amino acid pattern for 10-kilogram pigs. Journal of Animal Science, v.70, p.3102-3111, 1992.

CROMWELL, G. Amino acid supplements for pigs. (acessado em 01/12/2002) http://www.uky.edu/Ag/AnimalSciences/ swine/documents/aminoacidsupplementsforpigs.pdf, p.1-3, 1996.

De La LLATA, M.; DRITZ, S.S.; TOKACH, M.D. et al. Effects of increasing L-lysine $\mathrm{HCl}$ in corn- or sorghum-soybean meal-based diets on growth performance and carcass characteristics of growing-finishing pigs. Journal of Animal Science, v.80, p.2420-2432, 2002.

DONZELE, J.L.; COSTA, P.M.A.; ROSTAGNO, H.S. et al. Efeitos de níveis de energia digestíveis na composição da carcaça de suínos de cinco a quinze quilos. Revista da Sociedade Brasileira de Zootecnia, v.21, p.11001106, 1992.

EDMONDS, M.S.; ARENTSON, B.E.; MENTE, G.A. Effect of protein levels and space allocations on performance of growing-finishing pigs. Journal of Animal Science, v.76, p.814-821, 1998 . 
FERREIRA, R.A. Avaliação da redução da proteína bruta da ração com suplementação de aminoácidos para suínos de 15 a $60 \mathrm{~kg}$ mantidos em diferentes ambientes térmicos. Viçosa, MG: Universidade Federal de Viçosa, 2001. 67p. Tese (Doutorado em Zootecnia) - Universidade Federal de Viçosa, 2001.

FIGUEROA, J.L.; LEWIS, A.J.; MILLER, P.S. et al. Nitrogen metabolism and growth performance of gilts fed standard corn-soybean meal diets or low-crude protein, amino acidsupplemented diets. Journal of Animal Science, v.80, p.2911-2919, 2002.

FORD, A.L. Protein vs amino acids ...where less is better? Kempal Articles. www.kenpal.on.ca/ohfaf041.pdf, (acessado em 2003), p.1-3.

FÜLLER, M.F. Macronutrient requirements of growing swine. In: SIMPÓSIO INTERNACIONAL SOBRE EXIGÊNCIAS NUTRICIONAIS DE AVES E SUÍNOS, 1996, Viçosa, MG. Anais... Viçosa, MG: Universidade Federal de Viçosa, 1996. p.205-221.

GÓMEZ, R.S.; LEWIS, A.J.; MILLER, P.S. et al. Growth performance, diet apparent digestility, and plasma metabolite concentrations of barrows fed corn-soybean meal diets or low-protein, amino acid-supplementerented diets at different feeding levels. Journal of Animal Science, v.80, p.644$653,2002 \mathrm{a}$.

GÓMEZ, R.S.; LEWIS, A.J.; MILLER, P.S. et al. Body composition and tissue accretion rates of barrows fed cornsoybean meal diets or low-protein, amino acid-supplemented diets at different feeding levels. Journal of Animal Science, v.80, p.654-662, 2002b.

KERR, B.J.; EASTER, R.A. Effect of feeding reduced protein, amino acid-supplemented diets on nitrogen and energy balance in grower pigs. Journal of Animal Science, v.73, p.3000-3008, 1995.

KERR, B.J.; YEN, J.T.; NIENABER, J.A. et al. Influence of dietary protein level, amino acid supplementation, and environmental temperature on performance, body composition, organ weights and total heat production of growing pigs. Journal of Animal Science, v.81, p.19982007, 2003a.

KERR, B.J.; SOUTHERN, L.L.; BIDNER, K.G. et al. Influence of dietary protein level, amino acid supplementation, and dietary energy levels on growing-finishing pig performance and carcass composition. Journal of Animal Science, v.81, p.3075-3087, 2003b.

KENDALL, D.C.; LEMENAGER, K.M.; RICHERT, B.T. et al. Effects on intact protein diets versus reduced crude protein diets supplemented with synthetic amino acids on pig performance and ammonia levels in swine buildings. Swine Day Report, p.1-3, 1998.

Le BELLEGO, L.; NOBLET, J. Performance and utilization of dietary energy and amino acids in piglets fed low protein diets. Livestock Production Science, v.76, p.45-58, 2002.

Le BELLEGO, L.; Van MILGEN, J.; DUBOIS, S. et al. Energy utilization of low protein diets on growing pigs. Journal of Animal Science, v.79, p. 1259-1271, 2001.

MAHAN, D.C.; SHIELDS, R.G. Essential and nonessential amino acid composition of pigs from birth to 145 kilograms of body weigth, and comparison to other studies. Journal of Animal Science, v.76, p.513-521, 1998.
MÖHN, S.; De LANGE, C.F.M. The effect of body weight on the upper limit to protein deposition in a defined population of growing gilts. Journal of Animal Science, v.76, p.124$133,1998$.

OLIVEIRA, R.F.M. Efeito do nível de energia digestível e da temperatura ambiente sobre o desempenho e sobre parâmetros fisiológicos e hormonal de suínos dos $\mathbf{1 5}$ aos 30 kg. Viçosa, MG: Universidade Federal de Viçosa, 1996. 139p. Tese (Doutorado em Zootecnia) - Universidade Federal de Viçosa, 1996.

ORLANDO, U.A.D. Nível de proteína bruta da ração e efeito da temperatura ambiente sobre o desempenho e parâmetros fisiológicos de leitoas em crescimento. Viçosa, MG: Universidade Federal de Viçosa, 2001. 77p. Dissertação (Mestrado em Zootecnia) - Universidade Federal de Viçosa, 2001.

PIETERSE, E.; SIEBRITS, F.K.; GLOY, E.L. et al. The effect of protein inclusion level in diets formulated to contain an ideal amino acid composition for growing pigs. South African Journal of Animal Science, v.30 (suppl. 1), p.57-61, 2000.

REESE, D.E.; KOELSCH, R. Altering swine manure by diet modification. www.ianr.unl.edu/pubs/swine/g1390.htm, (Acessado em 2003), p.2, 2000.

RHODIMET nutrition guide. 2 ed. France: Rhône-Poulenc Animal Nutrition, 1993. 55p.

ROSTAGNO, H.S.; ALBINO, L.F.T.; DONZELE, J.L. et al. Composição de alimentos e exigências nutricionais de aves e suínos: Tabelas Brasileiras. Viçosa, MG: Universidade Federal de Viçosa, 2000. 141p.

SILVA, D.J. Análise de alimentos: métodos químicos e biológicos. Viçosa, MG: Universidade Federal de Viçosa, 1990. 166p.

TAVARES, S.L.S.; DONZELE, J.L.; OLIVEIRA, R.F.M. et al. Influência da temperatura ambiente sobre o desempenho e parâmetros fisiológicos de suínos machos castrados dos 30 aos $60 \mathrm{~kg}$. Revista Brasileira de Zootecnia, v.29, p.199-205, 2000.

TUITOEK, K.; YOUNG, L.G.; de LANGE, C.F.M. et al. The effect of reducing excess dietary amino acids on growing-finishing pig performance: Evalution of the ideal protein concept. Journal of Animal Science, v.75, p.1575-1583, 1997a.

TUITOEK, K.; YOUNG, L.G.; de LANGE, C.F.M. et al. Body composition and protein and fat accretion in various body components in growing gilts feed diets with different protein levels but estimatedto contain similar levels of ideal protein. Journal of Animal Science, v.75, p.1584-1590, 1997b.

UNIVERSIDADE FEDERAL DE VIÇOSA - UFV. SAEG (Sistema de Análises Estatísticas e Genéticas). Viçosa, MG (Versão 8.0). 2000. 